\title{
New oscillation theorems for a class of even-order neutral delay differential equations
}

\author{
Mona Anis ${ }^{1 *}$ and Osama Moaaz ${ }^{1,2}$
}

\section{"Correspondence:}

mona_anis1985@yahoo.com

'Department of Mathematics,

Faculty of Science, Mansoura

University, 35516 Mansoura, Egypt

Full list of author information is

available at the end of the article

\section{Springer}

\begin{abstract}
In this work, we study the oscillatory behavior of even-order neutral delay differential equations $v^{n}(I)+b(I) u(\eta(I))=0$, where $I \geq I_{0}, n \geq 4$ is an even integer and $v=u+a(u \circ \mu)$. By deducing a new iterative relationship between the solution and the corresponding function, new oscillation criteria are established that improve those reported in (T. Li, Yu.V. Rogovchenko in Appl. Math. Lett. 61:35-41, 2016).
\end{abstract}

MSC: $34 \mathrm{C} 10 ; 34 \mathrm{~K} 11$

Keywords: Even-order differential equations; Kneser solutions; Oscillatory solutions

\section{Introduction}

In this paper, we consider the even-order neutral differential equations

$$
v^{n}(t)+b(t) u(\eta(t))=0
$$

where $t \geq t_{0}>0, n \geq 4$ is an even natural number and $v:=u+a \cdot(u \circ \mu)$. Moreover, we suppose $a, b, \eta, \mu \in C\left(\left[t_{0}, \infty\right), \mathbb{R}\right), 0<a(t) \leq a_{0}, b(t) \geq 0, \mu(t) \leq t, b(t)$ is not identically zero for large $t$, and $\lim _{t \rightarrow \infty} \mu(t)=\lim _{t \rightarrow \infty} \eta(t)=\infty$.

By a solution of Eq. (1.1), we mean a function $u \in C\left(\left[t_{*}, \infty\right), \mathbb{R}\right), t_{*} \geq t_{0}$, which has the property $v \in C^{n}\left(\left[t_{0}, \infty\right), \mathbb{R}\right)$, and $u(t)$ satisfies Eq. (1.1) on $\left[t_{*}, \infty\right)$. We only focus on solutions of Eq. (1.1), which exist on $\left[t_{0}, \infty\right)$ and satisfy

$$
\sup \left\{|u(t)|: t_{u} \leq t\right\}>0 \quad \text { for every } t \geq t_{u} .
$$

As is customary, a solution of Eq. (1.1) is said to be oscillatory if it is neither eventually positive nor eventually negative on $\left[t_{0}, \infty\right)$ and otherwise, it is termed nonoscillatory.

The importance of studying neutral delay differential equations comes from their emergence when modeling many phenomena in different applied sciences, see [2, 3]. The qualitative theory of various classes of neutral differential equations has become an important area of research due to the fact that such equations arise in a variety of real world prob-

(c) The Author(s) 2021. This article is licensed under a Creative Commons Attribution 4.0 International License, which permits use, sharing, adaptation, distribution and reproduction in any medium or format, as long as you give appropriate credit to the original author(s) and the source, provide a link to the Creative Commons licence, and indicate if changes were made. The images or other third party material in this article are included in the article's Creative Commons licence, unless indicated otherwise in a credit line to the material. If material is not included in the article's Creative Commons licence and your intended use is not permitted by statutory regulation or exceeds the permitted use, you will need to obtain permission directly from the copyright holder. To view a copy of this licence, visit http://creativecommons.org/licenses/by/4.0/. 
lems such as in the study of non-Newtonian fluid theory and porous medium problems; see [4].

Very recently, a great development was found in the study of the oscillatory properties of solutions of second order neutral-delay differential equations; see for examples [5-17]. It would be interesting to extend this development to higher-order differential equations.

In 2016, Li and Rogovchenko [1] studied the oscillatory behavior of solutions of neutral delay equation (1.1). They used an approach similar to that used in [18], and established the relationship between $u$ and $v$ to have the form

$$
u(t) \geq \frac{1}{a\left(\mu^{-1}(t)\right)}\left(v\left(\mu^{-1}(t)\right)-\frac{v\left(\mu^{-1}\left(\mu^{-1}(t)\right)\right)}{a\left(\mu^{-1}\left(\mu^{-1}(t)\right)\right)}\right) .
$$

By using the comparison with the first-order delay equations, they obtained improved criteria over the previous ones in the literature.

In this paper, by improving the relationship (1.2), we establish a new criterion that improves the results in [1]. An example is given to illustrate the importance of our results.

In order to discuss our main results, we need the following auxiliary lemmas.

Lemma 1.1 ([19]) Assume that $\psi \in C^{n}\left(\left[t_{0}, \infty\right),(0, \infty)\right)$ and $\psi^{(n)}(t) \psi^{(n-1)}(t) \leq 0$ for $t \geq t_{1}$. If $\lim _{t \rightarrow \infty} \psi(t) \neq 0$, then there exists a $t_{\lambda} \in\left[t_{1}, \infty\right)$ such that

$$
\psi(t) \geq \frac{\lambda}{(n-1) !} t^{n-1}\left|\psi^{(n-1)}(t)\right|
$$

for all $t \in\left[t_{\lambda}, \infty\right)$ and $\lambda \in(0,1)$.

Lemma $1.2([20])$ Assume that the $\psi \in C^{(k+1)}\left(\left[t_{0}, \infty\right)\right)$ with $\psi^{(i)}(t)>0$ for $i=0,1,2, \ldots, k$ and $\psi^{(k+1)}(t) \leq 0$ for all $t \geq t_{1}$. Then there exists a $t_{\lambda} \in\left[t_{1}, \infty\right)$ such that

$$
\frac{h(t)}{h^{\prime}(t)} \geq \frac{\lambda t}{k}
$$

for all $t \in\left[t_{\lambda}, \infty\right)$ and $\lambda \in(0,1)$.

Lemma 1.3 ([21]) If $\psi \in C^{n}\left(\left[t_{0}, \infty\right),(0, \infty)\right), \psi^{(n)}(t)$ is eventually of one sign for large $t$, then there exist a $t_{u} \geq t_{0}$ and an integer $t \in[0, n]$ with $(-1)^{n+t} \psi^{(n)}(t) \geq 0$, such that $t>0$ yields

$$
\psi^{(k)}(t)>0, \quad t \geq t_{u}, k=0,1, \ldots, t-1
$$

and

$$
t \leq n-1 \quad \text { yields } \quad(-1)^{t+k} \psi^{(k)}(t)>0, \quad t \geq t_{u}, k=t, t+1, \ldots, n-1 .
$$

\section{Main results}

Through this section, we will be using the next notation: $\mu^{[-1]}:=\mu^{-1}, \mu^{-[h+1]}:=\mu^{-1} \circ \mu^{-[h]}$ for $h=1,2, \ldots$,

$$
\widetilde{a}(t):=\sum_{k=1}^{n / 2} \frac{1}{\sum_{m=1}^{2 k-1} a\left(\mu^{-[m]}(t)\right)}\left(1-\frac{1}{a\left(\mu^{-[2 k]}(t)\right)}\left(\frac{\mu^{-[2 k]}(t)}{\mu^{-[2 k-1]}(t)}\right)^{(n-1) / \lambda_{0}}\right),
$$




$$
\widehat{a}(t):=\sum_{k=1}^{n / 2} \frac{1}{\sum_{m=1}^{2 k-1} a\left(\mu^{-[m]}(t)\right)}\left(1-\frac{1}{a\left(\mu^{-[2 k]}(t)\right)}\left(\frac{\mu^{-[2 k]}(t)}{\mu^{-[2 k-1]}(t)}\right)^{1 / \lambda_{2}}\right),
$$

and

$$
B(t)=\min \left\{b\left(\eta^{-1}(t)\right), b\left(\eta^{-1}(\mu(t))\right)\right\},
$$

where $n$ is an even positive integer and $\lambda_{1}, \lambda_{2} \in(0,1)$.

Lemma 2.1 Assume that $u$ is an eventually positive solution. Then, we have two cases for the derivatives of $v$ as

$$
\begin{array}{ll}
\text { (1) } \quad v(t)>0, & v^{\prime}(t)>0, \quad v^{\prime \prime}(t)>0, \quad v^{(n-1)}(t)>0 \\
\text { (2) } \quad v(t)>0, & (-1)^{k+1} v^{(k)}(t)>0 \quad \text { for all } k \in\{1,2, \ldots, n-3\} .
\end{array}
$$

Proof From the definition of $v$, we get that $v(t)>0$ for large $t$. From Eq. (1.1), $v^{(n)}(t) \leq 0$. Based on the facts that $n$ is even and $v^{n}(t) \leq 0$, cases (1) and (2) are deduced directly from Lemma 1.3.

Theorem 2.1 Assume that $\mu^{\prime}(t)>0$ and there exists an even integer $m$ such that

$$
\frac{1}{a\left(\mu^{-[2 k]}(t)\right)}\left(\frac{\mu^{-[2 k]}(t)}{\mu^{-[2 k-1]}(t)}\right)^{(n-1) / \lambda_{0}} \leq 1
$$

for all $k=1,2, \ldots, n / 2$. Suppose that there exist functions $\chi \in C^{1}\left(\left[t_{0}, \infty\right), \mathbb{R}\right)$ and $\varkappa \in$ $C^{1}\left(\left[t_{0}, \infty\right), \mathbb{R}\right)$ satisfying

$$
\varkappa(t) \leq \eta(t), \quad \varkappa(t)<\mu(t), \quad \lim _{t \rightarrow \infty} \varkappa(t)=\infty
$$

and

$$
\chi(t) \leq \eta(t), \quad \chi(t)<\mu(t), \quad \chi^{\prime}(t) \geq 0, \quad \lim _{t \rightarrow \infty} \chi(t)=\infty .
$$

If there exist $\lambda_{i} \in(0,1), i=0,1,2$, such that the first-order delay equations

$$
G^{\prime}(t)+\frac{\lambda_{1}}{(n-1) !} b(t) \widetilde{a}(\eta(t))\left(\mu^{-1}(\varkappa(t))\right)^{n-1} G\left(\mu^{-1}(\varkappa(t))\right)=0
$$

and

$$
\phi^{\prime}(t)+\frac{\lambda_{2}}{(n-3) !} \mu^{-1}\left(\chi ( t ) \phi \left(\mu^{-1}(\chi(t)) \int_{t}^{\infty}(s-3)^{n-3} b(s) \widehat{a}(\eta(s)) \mathrm{d} s=0\right.\right.
$$

are oscillatory, every solution of Eq. (1.1) is oscillatory.

Proof Assume that Eq. (1.1) has an eventually positive solution $u$. It follows from (1.1) that $v^{n}(t)=-b(t) u(\eta(t)) \leq 0$. Thus, using Lemma 2.1, we see that there are two cases for the derivatives of $v$ for large $t$, either (1) or (2). 
Assume that (1) holds. Since $v$ is an increasing positive function, we obtain $\lim _{t \rightarrow \infty} v(t) \neq 0$. Therefore, by virtue of Lemma 1.1, we get

$$
v(t) \geq \frac{\lambda}{(n-1) !} t^{(n-1)} v^{(n-1)}(t)
$$

for every $\lambda \in(0,1)$ and for all large $t$. It follows from the definition of $v(t)$ that

$$
u(t)=\frac{1}{a\left(\mu^{-1}(t)\right)}\left(v\left(\mu^{-1}(t)\right)-u\left(\mu^{-1}(t)\right)\right)
$$

and

$$
u(t)=\frac{v\left(\mu^{-1}(t)\right.}{a\left(\mu^{-1}(t)\right)}-\frac{1}{a\left(\mu^{-1}(t)\right)}\left(\frac{v\left(\mu^{-1}\left(\mu^{-1}(t)\right)\right)}{a\left(\mu^{-1}\left(\mu^{-1}(t)\right)\right)}-\frac{u\left(\mu^{-1}\left(\mu^{-1}(t)\right)\right)}{a\left(\mu^{-1}\left(\mu^{-1}(t)\right)\right)}\right) .
$$

If we repeat the previous procedure, then there exists an even positive integer $n$ such that

$$
\begin{aligned}
u(t) & =\sum_{k=1}^{n} \frac{(-1)^{k+1}}{\sum_{m=1}^{k} a\left(\mu^{-[m]}(t)\right)} v\left(\mu^{-[k]}(t)\right)+\frac{1}{\sum_{m=1}^{n} a\left(\tau^{-[m]}(t)\right)} u\left(\mu^{-[n]}(t)\right) \\
& \geq \sum_{k=1}^{n} \frac{(-1)^{k+1}}{\sum_{m=1}^{k} a\left(\mu^{-[m]}(t)\right)} v\left(\mu^{-[k]}(t)\right) \\
& \geq \sum_{k=1}^{n / 2} \frac{1}{\sum_{m=1}^{2 k-1} a\left(\mu^{-[m]}(t)\right)}\left(v\left(\mu^{-[2 k-1]}(t)\right)-\frac{1}{a\left(\mu^{-[2 k]}(t)\right)} v\left(\mu^{-[2 k]}(t)\right)\right) .
\end{aligned}
$$

Now, using Lemma 1.2, we obtain

$$
\frac{v(t)}{v^{\prime}(t)} \geq \frac{\lambda_{0} t}{n-1}
$$

for all $\lambda_{0} \in(0,1)$ and $t \geq t_{1}$, and so

$$
\begin{aligned}
\left(\frac{v(t)}{t^{(n-1) / \lambda_{0}}}\right)^{\prime} & =\frac{v^{\prime}(t)}{t^{(n-1) / \lambda_{0}}}-\frac{n-1}{\lambda_{0}} \frac{v(t)}{t^{(n-1) / \lambda_{0}+1}} \\
& =\frac{t v^{\prime}(t)-\frac{n-1}{\lambda_{0}} v(t)}{t^{(n-1) / \lambda_{0}+1}} \leq 0 .
\end{aligned}
$$

Taking into account that $\mu(t) \leq t$, we get $\mu^{-[2 k-1]}(t) \leq \mu^{-[2 k]}(t)$. Thus, from (2.8), we find

$$
v\left(\mu^{-[2 k]}(t)\right) \leq v\left(\mu^{-[2 k-1]}(t)\right)\left(\frac{\mu^{-[2 k]}(t)}{\mu^{-[2 k-1]}(t)}\right)^{(n-1) / \lambda_{0}},
$$

which with (2.7) gives

$$
\begin{aligned}
u(t) \geq & \sum_{k=1}^{n / 2} \frac{1}{\sum_{m=1}^{2 k-1} a\left(\mu^{-[m]}(t)\right)} \\
& \times\left(1-\frac{1}{a\left(\mu^{-[2 k]}(t)\right)}\left(\frac{\mu^{-[2 k]}(t)}{\mu^{-[2 k-1]}(t)}\right)^{(n-1) / \lambda_{0}}\right) v\left(\mu^{-[2 k-1]}(t)\right) .
\end{aligned}
$$


Since $v^{\prime}(t)>0$ and $\mu^{-[2 k-1]}(t)>\mu^{-1}(t)$, we have that $v\left(\mu^{-[2 k-1]}(t)\right)>v\left(\mu^{-1}(t)\right)$ for all $k=$ $1,2, \ldots, n / 2$. Therefore, (2.9) becomes

$$
\begin{aligned}
u(t) & \geq v\left(\mu^{-1}(t)\right) \sum_{k=1}^{n / 2} \frac{1}{\sum_{m=1}^{2 k-1} a\left(\mu^{-[m]}(t)\right)}\left(1-\frac{1}{a\left(\mu^{-[2 k]}(t)\right)}\left(\frac{\mu^{-[2 k]}(t)}{\mu^{-[2 k-1]}(t)}\right)^{(n-1) / \lambda_{0}}\right) \\
& =\widetilde{a}(t) v\left(\mu^{-1}(t)\right),
\end{aligned}
$$

which, with the facts that $\varkappa(t) \leq \eta(t)$ and $\mu^{\prime}(t)>0$, gives

$$
u(\eta(t)) \geq \tilde{a}(\eta(t)) v\left(\mu^{-1}(\eta(t))\right) \geq \widetilde{a}(\eta(t)) v\left(\mu^{-1}(\varkappa(t))\right) .
$$

Then, Eq. (1.1) will become

$$
v^{n}(t)+b(t) \tilde{a}(\eta(t)) v\left(\mu^{-1}(\varkappa(t))\right) \leq 0
$$

Now, using Lemma 1.1, we arrive at

$$
v(t) \geq \frac{\lambda_{1}}{(n-1) !} t^{n-1} v^{(n-1)}(t)
$$

for all $\lambda_{1} \in(0,1)$. It follows from Eqs. (2.10) and (2.11) that

$$
v^{n}(t)+\frac{\lambda_{1}}{(n-1) !} b(t) \widetilde{a}(\eta(t))\left(\mu^{-1}(\varkappa(t))\right)^{n-1} v^{(n-1)}\left(\mu^{-1}(\varkappa(t))\right) \leq 0 .
$$

Clearly, $G(t):=v^{n-1}(t)$ is a positive solution of the first-order delay differential inequality

$$
G^{\prime}(t)+\frac{\lambda_{1}}{(n-1) !} b(t) \widetilde{a}(\eta(t))\left(\mu^{-1}(\varkappa(t))\right)^{n-1} G\left(\mu^{-1}(\varkappa(t))\right) \leq 0 .
$$

It follows from [22] that Eq. (2.6) also has a positive solution for all $\lambda_{0}, \lambda_{1} \in(0,1)$, but this contradicts our assumption.

Assume that (2) holds. It follows from Lemma 1.2 that

$$
v(t) \geq \lambda_{2} t v^{\prime}(t)
$$

for all $\lambda_{3} \in(0,1)$ and $t \geq t_{1} \geq t_{0}$, and so

$$
\left(\frac{v(t)}{t^{1 / \lambda_{2}}}\right)^{\prime}=\frac{v^{\prime}(t)}{t^{1 / \lambda_{2}}}-\frac{1}{\lambda_{2}} \frac{v(t)}{t^{\left(1+\lambda_{2}\right) / \lambda_{2}}}=\frac{1}{\lambda_{2}} \frac{\lambda_{2} t v^{\prime}(t)-v(t)}{t^{\left(1+\lambda_{2}\right) / \lambda_{2}}} \leq 0 .
$$

Thus, from the fact that $\mu^{-[2 k]}(t) \leq \mu^{-[2 k-1]}(t)$, we conclude that

$$
v\left(\mu^{-[2 k]}(t)\right) \leq\left(\frac{\mu^{-[2 k]}(t)}{\mu^{-[2 k-1]}(t)}\right)^{1 / \lambda_{2}} v\left(\mu^{-[2 k-1]}(t)\right)
$$


Combining (2.7) and (2.14), we obtain

$$
\begin{aligned}
u(t) \geq & \sum_{k=1}^{n / 2} \frac{1}{\sum_{m=1}^{2 k-1} a\left(\mu^{-[m]}(t)\right)} \\
& \times\left(1-\frac{1}{a\left(\mu^{-[2 k]}(t)\right)}\left(\frac{\mu^{-[2 k]}(t)}{\mu^{-[2 k-1]}(t)}\right)^{1 / \lambda_{2}}\right) v\left(\mu^{-[2 k-1]}(t)\right) .
\end{aligned}
$$

Since $\mu^{-[2 \kappa-1]}(t) \geq \mu^{-1}(t)$ for all $k=1,2, \ldots, n / 2$, (2.15) becomes

$$
u(t) \geq \widehat{a}(t) v\left(\mu^{-1}(t)\right) .
$$

Therefore, (1.1) will be

$$
v^{n}(t)+b(t) \widehat{a}(\eta(t)) v\left(\mu^{-1}(\eta(t))\right) \leq 0,
$$

which, with $\chi(t) \leq \eta(t)$ and $v^{\prime}(t)>0$, give

$$
v^{n}(t)+b(t) \widehat{a}(\eta(t)) v\left(\mu^{-1}(\chi(t))\right) \leq 0 .
$$

Integrating (2.17) from $t$ to $\infty$ consecutively $n-2$ times and using the properties of derivatives in case (2), we get

$$
v^{\prime \prime}(t)+\frac{1}{(n-3) !} v\left(\mu^{-1}(\chi(t)) \int_{t}^{\infty}(s-3)^{n-3} b(s) \widehat{a}(\eta(s)) \mathrm{d} s \leq 0 .\right.
$$

By setting $\phi(t)=v^{\prime}(t)$ and using (2.13), we conclude that $\phi(t)$ is a positive solution of the first-order delay differential inequality,

$$
\phi^{\prime}(t)+\frac{\lambda_{2}}{(n-3) !} \mu^{-1}\left(\chi ( t ) \phi \left(\mu^{-1}(\chi(t)) \int_{t}^{\infty}(s-3)^{n-3} b(s) \widehat{a}(\eta(s)) \mathrm{d} s \leq 0 .\right.\right.
$$

It follows from [22] that the Eq. (2.5) also has a positive solution, which contradicts our assumption. Therefore, the proof of this theorem is complete.

Corollary 2.1 Assume that there exist an even integer $m$ and functions $\varkappa \in C^{1}\left(\left[t_{0}, \infty\right), \mathbb{R}\right)$, $\chi \in C^{1}\left(\left[t_{0}, \infty\right), \mathbb{R}\right)$ such that $(2.1)-(2.3)$ hold. If

$$
\liminf _{t \rightarrow \infty} \int_{\mu^{-1}(\varkappa(t))}^{t} b(s) \widetilde{a}(\eta(s))\left(\mu^{-1}(\varkappa(s))\right)^{n-1} \mathrm{~d} s>\frac{(n-1) !}{\lambda_{1} \mathrm{e}}
$$

and

$$
\liminf _{t \rightarrow \infty} \int_{\mu^{-1}(\chi(t)}^{t} \mu^{-1}(\chi(\varrho))\left(\int_{\varrho}^{\infty}(s-3)^{n-3} b(s) \widehat{a}(\eta(s)) \mathrm{d} s\right) \mathrm{d} \varrho>\frac{(n-3) !}{\lambda_{2} \mathrm{e}}
$$

for some $\lambda_{i} \in(0,1), i=0,1,2$, every solution of Eq. (1.1) is oscillatory.

Proof Applying a well-known criterion [23, Theorem 2] for first-order delay differential equations (2.4) and (2.5) to be oscillatory, we obtain immediately the criteria (2.20) and (2.21), respectively. 
Remark 2.2 Combining Theorem 2.1 and the results reported in [24-26] for the oscillation of Eqs. (2.4) and (2.5), one can derive various oscillation criteria for Eq. (1.1).

By using a Riccati transformation, we obtain the following criterion.

Theorem 2.3 Assume that

$$
\left(\eta^{-1}(t)\right)^{\prime} \geq \eta_{0}>0, \quad \eta^{-1}(\mu(t)) \geq t, \quad \mu^{\prime}(t) \geq \mu_{0}>0
$$

and there exist an even integer $m$ and a function $\chi \in C^{1}\left(\left[t_{0}, \infty\right), \mathbb{R}\right)$ such that (2.1), (2.3) and (2.21) hold. If there exist $\lambda_{0} \in(0,1)$ and a function $\rho \in C^{1}\left(\left[t_{0}, \infty\right),(0, \infty)\right)$ such that

$$
\limsup _{t \rightarrow \infty} \int_{t_{1}}^{t}\left(\eta_{0} \rho(s) B(s)-\frac{(n-2) !}{4 \lambda_{0}}\left(1+\frac{a_{0}}{\mu_{0}}\right) \frac{\left(\rho^{\prime}(s)\right)^{2}}{s^{(n-2)} \rho(s)}\right) \mathrm{d} s=\infty
$$

then every solution of Eq. (1.1) is oscillatory.

Proof Assume that Eq. (1.1) has an eventually positive solution $u$. It follows from (1.1) that $v^{n}(t)=-b(t) u(\eta(t)) \leq 0$. Thus, using Lemma 2.1, we have that there are two cases for the derivatives of $v$ for large $t$, either (1) or (2).

Assume that (1) holds. From Eq. (1.1), we obtain

$$
\frac{1}{\left(\eta^{-1}(t)\right)^{\prime}}\left(v^{(n-1)}\left(\eta^{-1}(t)\right)\right)^{\prime}+b\left(\eta^{-1}(t)\right) u(t)=0
$$

and

$$
\frac{1}{\left(\eta^{-1}(\mu(t))\right)^{\prime}}\left(v^{(n-1)}\left(\eta^{-1}(\mu(t))\right)\right)^{\prime}+b\left(\eta^{-1}(\mu(t))\right) u(\mu(t))=0 .
$$

Combining (2.24) and (2.25), and using (2.22), we find

$$
\begin{aligned}
& \frac{1}{\eta_{0}}\left(v^{(n-1)}\left(\eta^{-1}(t)\right)\right)^{\prime}+\frac{a_{0}}{\eta_{0} \mu_{0}}\left(v^{(n-1)}\left(\eta^{-1}(\mu(t))\right)\right)^{\prime} \\
& \quad+b\left(\eta^{-1}(t)\right) u(t)+a_{0} b\left(\eta^{-1}(\mu(t))\right) u(\mu(t)) \leq 0,
\end{aligned}
$$

and so

$$
\frac{1}{\eta_{0}}\left(v^{(n-1)}\left(\eta^{-1}(t)\right)\right)^{\prime}+\frac{a_{0}}{\eta_{0} \mu_{0}}\left(v^{(n-1)}\left(\eta^{-1}(\mu(t))\right)\right)^{\prime}+B(t)\left(u(t)+a_{0} u(\mu(t))\right) \leq 0 .
$$

Then,

$$
\frac{1}{\eta_{0}}\left(v^{(n-1)}\left(\eta^{-1}(t)\right)+\frac{a_{0}}{\mu_{0}} v^{(n-1)}\left(\eta^{-1}(\mu(t))\right)\right)^{\prime}+B(t) v(t) \leq 0
$$

Now, we define the Riccati transformation as

$$
\varpi(t):=\rho(t) \frac{v^{(n-1)}\left(\eta^{-1}(t)\right)}{v(t)}
$$


Thus, $\varpi(t)>0$ for $t \geq t_{1} \geq t_{0}$, and

$$
\varpi^{\prime}(t)=\frac{\rho^{\prime}(t)}{\rho(t)} \varpi(t)-\rho(t)\left(\frac{\left(v^{(n-1)}\left(\eta^{-1}(t)\right)\right) v^{\prime}(t)}{v^{2}(t)}-\frac{\left(v^{(n-1)}\left(\eta^{-1}(t)\right)\right)^{\prime}}{v(t)}\right) .
$$

Using Lemma 1.1 and the fact that $v^{(n)} \leq 0$, we arrive at

$$
\begin{aligned}
v^{\prime}(t) & \geq \frac{\lambda_{0}}{(n-2) !} t^{n-2} v^{(n-1)}(t) \geq \frac{\lambda_{0}}{(n-2) !} t^{n-2} v^{(n-1)}\left(\eta^{-1}(\mu(t))\right) \\
& \geq \frac{\lambda_{0}}{(n-2) !} t^{n-2} v^{(n-1)}\left(\eta^{-1}(t)\right) .
\end{aligned}
$$

Hence, (2.27) yields

$$
\varpi^{\prime}(t) \leq \frac{\rho^{\prime}(t)}{\rho(t)} \varpi(t)-\frac{\lambda_{0}}{(n-2) !} \frac{t^{(n-2)}}{\rho(t)} \varpi^{2}(t)+\rho(t) \frac{\left(v^{(n-1)}\left(\eta^{-1}(t)\right)\right)^{\prime}}{v(t)} .
$$

Next, we define function

$$
\omega(t):=\rho(t) \frac{v^{(n-1)}\left(\eta^{-1}(\mu(t))\right)}{v(t)} .
$$

Then $\omega(t)>0$ for $t \geq t_{1} \geq t_{0}$ and

$$
\begin{aligned}
\omega^{\prime}(t) & =\frac{\rho^{\prime}(t)}{\rho(t)} \omega(t)-\rho(t)\left(\frac{\left(v^{(n-1)}\left(\eta^{-1}(\mu(t))\right)\right) v^{\prime}(t)}{v^{2}(t)}-\frac{\left(v^{(n-1)}\left(\eta^{-1}(\mu(t))\right)\right)^{\prime}}{v(t)}\right) \\
& \leq \frac{\rho^{\prime}(t)}{\rho(t)} \omega(t)-\frac{\lambda_{0}}{(n-2) !} \frac{t^{(n-2)}}{\rho(t)} \omega^{2}(t)+\rho(t) \frac{\left(v^{(n-1)}\left(\eta^{-1}(\mu(t))\right)\right)^{\prime}}{v(t)} .
\end{aligned}
$$

Combining (2.29) and (2.30), we get

$$
\begin{aligned}
\varpi^{\prime}(t)+\frac{a_{0}}{\mu_{0}} \omega^{\prime}(t) \leq & \frac{\rho^{\prime}(t)}{\rho(t)} \varpi(t)-\frac{\lambda_{0}}{(n-2) !} \frac{t^{(n-2)}}{\rho(t)} \varpi^{2}(t)+\frac{a_{0}}{\mu_{0}}\left[\frac{\rho^{\prime}(t)}{\rho(t)} \omega(t)\right. \\
& \left.-\frac{\lambda_{0}}{(n-2) !} \frac{t^{(n-2)}}{\rho(t)} \omega^{2}(t)\right]-\eta_{0} \rho(t) B(t) .
\end{aligned}
$$

Using the fact that

$$
H y-K y^{2} \leq \frac{1}{4} \frac{H^{2}}{K}, \quad K>0,
$$

we obtain

$$
\varpi^{\prime}(t)+\frac{a_{0}}{\mu_{0}} \omega^{\prime}(t) \leq \frac{(n-2) !}{4 \lambda_{0}}\left(1+\frac{a_{0}}{\mu_{0}}\right) \frac{\left(\rho^{\prime}(t)\right)^{2}}{t^{(n-2)} \rho(t)}-\eta_{0} \rho(t) B(t) .
$$

Integrating the above inequality from $t_{1}$ to $t$, we have

$$
\int_{t_{1}}^{t}\left(\eta_{0} \rho(s) B(s)-\frac{(n-2) !}{4 \lambda_{0}}\left(1+\frac{a_{0}}{\mu_{0}}\right) \frac{\left(\rho^{\prime}(s)\right)^{2}}{s^{(n-2)} \rho(s)}\right) \mathrm{d} s \leq \varpi\left(t_{1}\right)+\frac{a_{0}}{\mu_{0}} \omega\left(t_{1}\right)
$$

which contradicts (2.23). 
Assume that case (2) holds. If we are back to the proof of Corollary 2.1, then we get a contradiction with (2.21). Hence, the proof is complete.

Next, we give an example to illustrate our main results.

Example 2.1 Consider a fourth-order neutral delay differential equation

$$
\left(u(t)+a_{0} u(\beta t)\right)^{(4)}+\frac{b_{0}}{t^{4}} u(\delta t)=0, \quad t \geq 1
$$

where $a_{0}, b_{0}>0$ and $0<\delta \leq \beta<1$. It is easy to see that $B(t)=\left(b_{0} \delta^{4}\right) / t^{4}$,

$$
\widetilde{a}(t)=\left(1-\frac{1}{\beta^{3 / \lambda} a_{0}}\right) \sum_{k=1}^{n / 2} \frac{1}{a_{0}^{2 k-1}}:=A_{0}
$$

and

$$
\widehat{a}(t):=\left(1-\frac{1}{\beta^{1 / \lambda_{2}} a_{0}}\right) \sum_{k=1}^{n / 2} \frac{1}{a_{0}^{2 k-1}}:=A_{1} .
$$

By choosing $\varkappa(t)=\chi(t)=\delta t$, we see that (2.2) and (2.3) hold, and conditions (2.20) and (2.21) reduce to

$$
b_{0} \ln \frac{\beta}{\delta}>\frac{6 \beta^{3}}{\delta^{3} A_{0} \mathrm{e}}
$$

and

$$
b_{0} \ln \frac{\beta}{\delta}>\frac{12 \beta}{\delta A_{1} \mathrm{e}}
$$

respectively. Thus, from Corollary 2.1, we see that every solution of Eq. (2.31) is oscillatory if

$$
b_{0}>\max \left\{\frac{6 \beta^{3}}{\delta^{3} A_{0} \mathrm{e} \ln \beta / \delta}, \frac{12 \beta}{\delta A_{1} \mathrm{e} \ln \beta / \delta}\right\} .
$$

Moreover, the condition (2.23) reduces to

$$
\limsup _{t \rightarrow \infty} \int_{t_{1}}^{t}\left(\delta^{4} \eta_{0} b_{0}-\frac{9}{2 \lambda_{0}}\left(1+\frac{a_{0}}{\mu_{0}}\right)\right) \frac{1}{s} \mathrm{~d} s=\infty
$$

when

$$
b_{0}>\frac{9}{2}\left(1+\frac{a_{0}}{\mu_{0}}\right) \frac{1}{\delta^{4} \eta_{0}} .
$$

Thus, from Theorem 2.3, we see that every solution of Eq. (2.31) is oscillatory if

$$
b_{0}>\max \left\{\frac{9}{2}\left(1+\frac{a_{0}}{\mu_{0}}\right) \frac{1}{\delta^{4} \eta_{0}}, \frac{6 \beta^{3}}{\delta^{3} A_{0} \mathrm{e} \ln \beta / \delta}\right\} .
$$


Remark 2.4 Although the results of Li and Rogovchenko in [1] improved their previous results, they used Lemma 1.2 with $\lambda=1$ (and this is inaccurate); see Remark 12 in [20]. Theorem 2.1, with $n=2$, is a correction of Theorem 2.1 in [1]. Moreover, our results improve the results in [1], since the iterative nature of the two functions $\widetilde{a}(t)$ and $\widehat{a}(t)$ enables us to test for oscillations, even when the previously known results fail to apply. Let us consider a special case of (2.31), namely,

$$
(u(t)+10 u(0.9 t))^{(4)}+\frac{110}{t^{4}} u(0.5 t)=0 .
$$

We note that the condition (2.32) fail to apply on (2.33) when $n=2,4$ (consequently, the results in [1] also fail). But, at $n=6$, the condition (2.32) is satisfied. Therefore, our results improve the previous results in the literature.

Remark 2.5 It would be of interest to further investigate Eq. (1.1) with different neutral coefficients; see [27] and [28] for more details. It would also be interesting to extend this development to higher-order nonlinear neutral differential equations.

\section{Acknowledgements}

The author is grateful to the editors and two anonymous referees for a very thorough reading of the manuscript and for pointing out some inaccuracies.

\section{Funding}

Not applicable.

\section{Availability of data and materials}

Not applicable.

\section{Competing interests}

The authors declare that they have no competing interests.

Authors' contributions

The authors equally conceived of the study. All authors read and approved the final manuscript.

\section{Author details}

'Department of Mathematics, Faculty of Science, Mansoura University, 35516 Mansoura, Egypt. ${ }^{2}$ Section of Mathematics, International Telematic University Uninettuno, CorsoVittorio Emanuele II, 39, 00186 Roma, Italy.

\section{Publisher's Note}

Springer Nature remains neutral with regard to jurisdictional claims in published maps and institutional affiliations.

Received: 6 January 2021 Accepted: 9 May 2021 Published online: 17 May 2021

\section{References}

1. Li, T., Rogovchenko, Yu.V.: Oscillation criteria for even-order neutral differential equations. Appl. Math. Lett. 61, 35-41 (2016)

2. Gyori, I., Ladas, G.: Oscillation Theory of Delay Differential Equations with Applications. Clarendon Press, Oxford (1991)

3. Hale, J.K.: Functional Differential Equations, in Analytic Theory of Differential Equations. Springer, Berlin (1971)

4. Li, T., Pintus, N., Viglialoro, G.: Properties of solutions to porous medium problems with different sources and boundary conditions. Z. Angew. Math. Phys. 70(3), Art. 86, 1-18 (2019)

5. Bohner, M., Grace, S.R., Jadlovská, I.: Oscillation criteria for second-order neutral delay differential equations. Electron. J. Qual. Theory Differ. Equ. 2017,60, 1-12 (2017)

6. Bohner, M., Grace, S.R., Jadlovská, I.: Sharp oscillation criteria for second-order neutral delay differential equations. Math. Methods Appl. Sci. 43(17), 10041-10053 (2020)

7. Chatzarakis, G.E., Moaaz, O., Li, T., Qaraad, B.: Some oscillation theorems for nonlinear second-order differential equations with an advanced argument. Adv. Differ. Equ. 2020(1), 160 (2020)

8. Džurina, J., Grace, S.R., Jadlovská, I., Li, T.: Oscillation criteria for second-order Emden-Fowler delay differential equations with a sublinear neutral term. Math. Nachr. 293(5), 910-922 (2020)

9. Grace, S.R., Džurina, J., Jadlovská, I., Li, T.: An improved approach for studying oscillation of second-order neutral delay differential equations. J. Inequal. Appl. 2018, 193 (2018)

10. Li, T., Rogovchenko, Yu.V.: Oscillation of second-order neutral differential equations. Math. Nachr. 288(10), 1150-1162 (2015) 
11. Li, T., Rogovchenko, Yu.V:: Oscillation criteria for second-order superlinear Emden-Fowler neutral differential equations. Monatshefte Math. 184(3), 489-500 (2017)

12. Li, T., Rogovchenko, Yu.V., Zhang, C.: Oscillation of second-order neutral differential equations. Funkc. Ekvacioj 56(1), $111-120(2013)$

13. Moaaz, O: New criteria for oscillation of nonlinear neutral differential equations. Adv. Differ. Equ. 2019, 484 (2019)

14. Moaaz, O., Ramos, H., Awrejcewicz, J.: Second-order Emden-Fowler neutral differential equations: a new precise criterion for oscillation. Appl. Math. Lett. 118, 107172 (2021)

15. Moaaz, O., Chatzarakis, G.E., Abdeljawad, T., Cesarano, C., Nabih, A.: Amended oscillation criteria for second-order neutral differential equations with damping term. Adv. Differ. Equ. 2020(1), 553 (2020)

16. Moaaz, O., Bazighifan, O.: Oscillation criteria for second-order quasi-linear neutral functional differential equation. Discrete Contin. Dyn. Syst., Ser. B 13(9), 2465-2473 (2020)

17. Moaaz, O., Anis, M., Baleanu, D., Muhib, A.: More effective criteria for oscillation of second-order differential equations with neutral arguments. Mathematics 8(6), 986 (2020)

18. Agarwal, R.P., Bohner, M., Li, T., Zhang, C.: A new approach in the study of oscillatory behavior of even-order neutral delay differential equations. Appl. Math. Comput. 225, 787-794 (2013)

19. Agarwal, R.P., Grace, S.R., O'Regan, D.: Oscillation Theory for Difference and Functional Differential Equations. Kluwer Academic, Dordrecht (2000)

20. Chatzarakis, G.E., Grace, S.R., Jadlovská, I., Li, T., Tunç, E.: Oscillation criteria for third-order Emden-Fowler differential equations with unbounded neutral coefficients. Complexity 2019, Art. 5691758 (2019)

21. Philos, Ch.G.: A new criterion for the oscillatory and asymptotic behavior of delay differential equations. Bull. Acad. Pol. Sci., Sér. Sci. Math. 39, 61-64 (1981)

22. Philos, Ch.G.: On the existence of nonoscillatory solutions tending to zero at $\infty$ for differential equations with positive delays. Arch. Math. 36, 168-178 (1981)

23. Kitamura, Y., Kusano, T.: Oscillation of first-order nonlinear differential equations with deviating arguments. Proc. Am. Math. Soc. 78(1), 64-68 (1980)

24. Chatzarakis, G.E., Jadlovská, I., Li, T.: Oscillations of differential equations with non-monotone deviating arguments, Adv. Differ. Equ. 2019, Art. 233, 1-20 (2019)

25. Chatzarakis, G.E., Li, T.: Oscillations of differential equations generated by several deviating arguments. Adv. Differ. Equ. 2017, Art. 292, 1-24 (2017)

26. Chatzarakis, G.E., Li, T.: Oscillation criteria for delay and advanced differential equations with nonmonotone arguments. Complexity 2018, Art. 8237634, 1-18 (2018)

27. Chatzarakis, G.E., Džurina, J., Jadlovská, l.: A remark on oscillatory results for neutral differential equations. Appl. Math. Lett. 90, 124-130 (2019)

28. Li, T., Rogovchenko, Yu.V.: On the asymptotic behavior of solutions to a class of third-order nonlinear neutral differential equations. Appl. Math. Lett. 105, Art. 106293, 1-7 (2020)

\section{Submit your manuscript to a SpringerOpen ${ }^{\circ}$ journal and benefit from:}

- Convenient online submission

- Rigorous peer review

- Open access: articles freely available online

- High visibility within the field

- Retaining the copyright to your article

Submit your next manuscript at $\boldsymbol{\nabla}$ springeropen.com 